\title{
Resistencias 2.0: Nuevas prácticas comunicativas e informacionales para confrontar el extractivismo minero en Colombia*
}

\author{
Aída Julieta Quiñones-Torres ${ }^{* *}$ \\ Alfredo Luis Menéndez-Echavarría*** \\ Héctor Herrera-Santoyo ${ }^{\star * * *}$ \\ Recibido: 2016-04-20 Enviado a pares: 2016-05-09 Aprobado por \\ pares: 2016-05-25 Aceptado: 2016-06-10 \\ DOI: 10.22395/angr.v15n29a2
}

\begin{abstract}
Resumen
Las dos últimas décadas se han convertido para Colombia en un campo propicio para la inversión extranjera directa (IED), principalmente en materia de recursos naturales de los cuales se destaca el extractivismo minero. No obstante, dadas las características del país relacionadas con la riqueza cultural, hídrica y biodiversa, se ha levantado resistencia de comunidades pertenecientes a pueblos étnicos, campesinos y urbanos, que dicen «no a la minería y por la defensa de la vida, los territorios y los bienes comunes). El presente artículo da cuenta de la incidencia del uso de plataformas colaborativas de comunicación relativas a la web social, las cuales se articulan en el marco de las mediaciones alternativas, cuyo fin es activar tejidos comunicativos que coadyuvan a las luchas entendidas como resistencias, enfocadas en detener la gran minería, que se instala sobre la base de políticas y normas que irrumpen los territorios, impactando la vida de diversas poblaciones sobre las que recaen estos proyectos extractivos.
\end{abstract}

Palabras clave: resistencias, gran minería, mediaciones alternativas, plataformas colaborativas, tejidos comunicativos.

\footnotetext{
Este artículo está vinculado con la investigación "Resistencias frente a la expansión minera los casos de la Toma y La Colosa" (Vicerrectoría de Investigación, Pontificia Universidad Javeriana). De igual forma, se deriva de la investigación: «Tendencias investigativas de la Ciencia de la Información y la Bibliotecología en Iberoamérica y El Caribe» (ID 5510, Vicerrectoría de Investigación, Pontificia Universidad Javeriana). Red por la Justicia Ambiental en Colombia (Bogotá, D. C., Colombia) y Asociación Interamericana para la Defensa del Ambiente (AIDA) (COLOMBIA)

"* Profesora asistente de tiempo completo del Departamento de Ciencia de la Información, Facultad de Comunicación y Lenguaje, Pontificia Universidad Javeriana (Bogotá, D. C., Colombia). Licenciada en Filosofía, magíster en Filosofía, magíster en Estudios Políticos y candidata a doctora en Estudios Ambientales y Rurales de la Pontificia Universidad Javeriana. aquinones@javeriana.edu.co

** Profesor asistente de tiempo completo del Departamento de Ciencia de la Información, Facultad de Comunicación y Lenguaje, Pontificia Universidad Javeriana (Bogotá, D. C., Colombia). Profesional en Publicidad de la Universidad de Bogotá Jorge Tadeo Lozano, Especialista en Redes de Información Documental y magíster en Educación de la Pontificia Universidad Javeriana. menendez@javeriana.edu.co

... Coordinador de la Red por la Justicia Ambiental en Colombia (Bogotá, D. C., Colombia) y Asesor Legal de la Asociación Interamericana para la Defensa del Ambiente (AIDA). Abogado de la Universidad de Los Andes y magíster en Políticas Públicas de la Universidad Nacional de Colombia. hherrera@aida-americas.org
} 


\title{
Resistances 2.0: New Communication and Information Practices for Challenging Mining Extraction in Colombia
}

\begin{abstract}
The last two decades have become a very good field for foreign direct investment in Colombia (IED), mainly in natural resources from which the mining extractions have been outstanding. However, due to the characteristic of the country in cultural, hydric, and biodiversity richness, there has appeared a resistance of communities belonging to ethnic groups, peasants, and urban people, stating "no to mining, for the defense of live, territories and common goods." This article refers to the incidence of the use of communicative collaboration platforms, related to social web, which articulate in the framework of alternative mediations, whose purpose is to active communicative networks helping the fights understood as resistances, focused on stopping the big mining, installed on the base of policies and norms which introduce themselves in territories impacting the life of diverse population on which this extraction projects fall..
\end{abstract}

Key words: resistances, big mining, alternative mediations, collaborative platforms, communicative networks. 


\section{Introducción}

En las últimas décadas, Colombia ha implementado una serie de cambios que ponen en el centro del crecimiento económico los proyectos extractivos como parte del eje de productividad y competitividad que se traza para la región. Con este enfoque, se propicia un ambiente para que el país adopte una serie de políticas, legislación y normativa, cuyo fin es atraer la inversión extranjera directa (IED), relacionada con la denominada industria extractiva. De este modo, el sector de la minería, que se desarrolla a gran escala, ha recibido grandes concesiones, que benefician principalmente a empresas extranjeras que buscan "orientar sus inversiones hacia nuevos proyectos mineros y/o ampliaciones" (Saade Hazin, 2013, p. 9).

En tal sentido, los proyectos mineros han sido declarados como prioritarios para el avance de la economía nacional, y han incluidos en políticas como Colombia País Minero del año 2010 y el Plan de Desarrollo Nacional 2010-2014, alrededor del eje denominado locomotora minero-energética; el Plan de Desarrollo 2014-2018 enfatiza que una de las principales fuentes de financiamiento provendrá de los recursos minero energéticos (Departamento Nacional de Planeación de Colombia, 2015). Asimismo, se establece la minería como Proyecto de Interés Nacional (PIN), y se han dictado decretos, como el 934 de $2013^{1}$ (Consejo de Estado de Colombia, Sala de lo Contencioso-Administrativo, 2013), que irrumpen directamente en los espacios de decisión local. Estas, entre otras decisiones, han demostrado la prioridad del extractivismo para el país.

Sin embargo, desde la perspectiva económica orientada al desarrollo, algunos analistas observan que, cuando el país logró sus mayores exportaciones y alcanzó un avance de la IED, se tomó el camino de ampliar la deuda externa a partir de 2009, y se proyectó que los pagos de tal endeudamiento se harían con los recursos naturales (Pardo, 2015), ampliando el horizonte para acelerar y aumentar las concesiones mineras a empresas extranjeras, cuya consecuencia ha sido la generación de conflictos socio-ambientales.

Con todo, se deduce que el carácter extractivo de estas actividades mineras genera una serie de impactos ambientales y sociales adversos, ligados a la biodiversidad, a la "contaminación de los recursos (agua, tierras, aire, etc.), (...) desplazamiento de poblaciones o uso de lugares con significado especial para los habitantes originarios de las localidades en cuestión" (Saade Hazin, 2013, p. 9). Luego, el avance de titulación minera en Colombia, tanto como la expansión que se proyecta en solicitudes, y que se expresa en la Resolución 045 del 20 de junio del 2012 de la Agencia Nacional de Minería, prevé concesión de "22,3 millones de hectáreas, |advirtiendo que las áreas] con interés minero abarcan cerca de cuarenta (40) millones de hectáreas" (Garay Salamanca, 2013, p. 24).

Actualmente, la Sección Tercera del Consejo de Estado de manera provisional ha suspendido el Decreto 934 del 2013, pues en su consideración vulnera el principio de autonomía a territorial (Consejo de Estado Sala de lo Contencioso-Administrativo Sección tercera, subsección A, 2014). 
En suma, significa que se impactarán vastas regiones rurales caracterizadas como áreas de protección legal, así como territorios étnicos y campesinos; del mismo modo, se verán impactados territorios urbanos que presentan actualmente titulación minera o sobre los que indirectamente recae este tipo de conflictos. Para el caso de la protección legal, se ha demostrado que muchas de las zonas que deberían quedar excluidas de la minería, tales como páramos y parques naturales, han sido objeto de títulos mineros. Asimismo, áreas catalogadas de restricción como zonas de reserva han quedado expuestas, ya que existe la posibilidad de solicitar sustracción para proceder a desarrollar actividades mineras (Congreso de la República de Colombia, 2001). Se destaca, de acuerdo con el reporte de Catastro Minero en diciembre de 2013, una evidencia de 833 títulos, cruzados total o parcialmente con áreas demarcadas de protección legal (Cabrera, 2014).

Frente a este panorama, se han venido configurando en el país importantes movilizaciones, desde las cuales se activan las resistencias, que articulan tejidos comunicativos a través de mediaciones alternativas, que coadyuvan a las luchas enfocadas en detener la gran minería. Como parte de estas mediaciones, se acentúa el uso de diversos medios, como las plataformas colaborativas de comunicación conexas a la web social, a través de las cuales se transmite lo que otros medios opacan, procurando, de este modo, transparencia informativa que permita desvelar las demandas sobre el impacto en la riqueza hídrica, la biodiversidad, la cultural y la vida cotidiana, afectadas por la irrupción minera que provoca conflictos sociales y ambientales.

Con este fin, el objetivo propuesto en este artículo es demostrar cómo la puesta en marcha de mediaciones, a través plataformas concebidas como medios sociales basados en la Web 2.0, se convierte en una práctica de resistencia, en tanto, contribuye a la transparencia informativa, a la vez que crea tejidos comunicativos; se trata, entonces, de informar, comunicar y crear contenidos que desvelen este tipo de conflictos, como aquellos que provoca la gran minería a cielo abierto, con sus efectos devastadores.

A partir de este enfoque, el presente artículo se divide en cuatro partes que buscan establecer el contexto de aplicación de estos medios sociales; un primer momento, en el cual se presenta el planteamiento metodológico, argumentando el modo como se asume la investigación. Un segundo momento por medio del cual se aportan referentes teóricos, cuyo fin es resaltar la importancia que tienen las mediaciones comunicativas, desde medios sociales posicionados como recursos de información y comunicación alternativa; asimismo, se esboza un estado del arte sobre el uso de los mismos. Un tercer momento en el cual se plantea la descripción y desarrollo de recursos seleccionados, en tanto intervenimos el diseño de algunos; o en el rol como seguidores, y también por la interacción pedagógica que ofrecen. Un cuarto momento presenta la articulación de los resultados, y la discusión, dando cuenta del alcance de este tipo de mediaciones. Finalmente, presentamos las conclusiones, que evidencian cómo las mediaciones estimulan una vía que debe ser alimentada para lograr, tanto mayor alcance, como contribución a la resistencia, viabilizando sus demandas. 


\section{Metodología}

El desarrollo metodológico se fundamenta en un enfoque mixto que integra investigación cualitativa y cuantitativa, al tiempo que se asume la investigación documental. En perspectiva cualitativa nos situamos desde la Investigación Acción Colectiva (Botero, 2012), cuyo fundamento es la militancia que se entiende como un "pensar y actuar con quienes estamos afectados, comunidades autoras y co-actuantes hacia un tipo de práctica investigativa capaz de articular implicación, pensamiento, afectación y acción” (p. 7). A este enfoque se suma el diálogo de saberes, por cuanto se vinculan visiones diferentes que provienen del conocimiento técnico y de los saberes populares. Cabe argumentar que somos parte de esta interacción comunicativa, expresada desde la resistencia, y así hemos creado herramientas para desvelar los conflictos que provoca esta actividad extractiva. Por tanto, el tipo de investigación cualitativa que ha sido seleccionada da cuenta del vínculo directo en las acciones.

En nuestra investigación, activistas y militantes potenciamos la autoobservación, que se entiende como aquella por medio de la cual el observador "habla desde su experiencia como actor" (Delgado y Gutiérrez, 1999. p. 167). Asimismo, se plantea la práctica de las redes conversacionales que son interpretadas según Flores (citado en Delgado \& Gutiérrez, 1999) como "conversaciones para la acción y conversaciones para crear posibilidades" (p. 384). Es decir, este tejido nos permite no solo coherencia con la investigación activista y militante, sino que posibilita validez y reconocimiento desde otras nociones de rigor.

Desde una perspectiva cuantitativa, se analizan las estadísticas reportadas con un alto nivel de detalle en los sitios web y redes sociales como Facebook y Twitter. Esta interacción en Internet es medida o contabilizada por los mismos proveedores de servicios informáticos. El seguimiento al blog: Acción Colectiva y Megaproyectos Mineros (2016) cuantifica la estadística neta de visitas desde su creación en mayo de 2011, hasta mayo de 2016. Para el análisis de la comunidad de Facebook, Conciencia Campesina, se mide la cantidad de 'Me gusta', acumulados desde su apertura en 2009 hasta mayo de 2016, interpretando este 'Me gusta' como interés o respaldo a la información que presenta la comunidad.

En el caso de la cuenta de Twitter de la Red por la Justicia Ambiental en Colombia (RJAColombia, 2016), se acogen las estadísticas que el servicio de analistas de Twitter provee a sus usuarios. A partir de este, se identifican las cifras de seguidores en los últimos dos años, desarrollando un análisis interpretativo y de contraste con el nivel de vistas, interacciones, respuestas y clics en los enlaces del último mes.

Tomamos finalmente, la investigación documental (Hoyos, 2008), considerada sustancial, por cuanto el seguimiento a documentos nos provee de argumentos que sustentan el fundamento de la comunicación como una forma de mediación desde los medios sociales, considerados recursos de información y de comunicación alternativos. De acuerdo con Hoyos (2008), la exploración documental implica compromiso personal, profesional, ético, epistemológico y metodológico, al que agregamos el político. 


\section{Referentes teóricos y estado del arte}

En la actualidad, los medios sociales se están posicionando como recursos de información y de comunicación alternativos para promover y compartir ideas, gestionar el branding personal o corporativo, y también como se plantea en este estudio, convocar o servir al fortalecimiento interno de la movilización social en perspectiva de resistencia y transformación de conflictos que afectan a la sociedad. Menéndez Echavarría y Sánchez Hernández (2013) definen los medios sociales como aquellas "plataformas interactivas de comunicación que permiten a las personas colaborar entre ellas, generar contenidos, compartir información y conocimiento, y participar a través de herramientas tecnológicas de la web 2.0 o web social" (p. 154).

No obstante, aunque son dispositivos de poder y control, igualmente son observados como instrumentos de comunicación que proporcionan datos, información y conocimiento, donde las sociedades optan por una lectura, reflexiva y crítica de los contenidos «socialmediáticos», para comprender lo que se expone en los ambientes digitales. Es así como la generación conectada avista el potencial de las herramientas como aliadas en los procesos de resistencia, en las que los sujetos ejercen incidencia en cuestiones políticas, sociales, económicas y normativas.

Mayfield (2008) propone una clasificación de los medios sociales que a continuación se describe:

- Redes sociales: comprendidos como escenarios digitales, de carácter personal, profesional y, agregamos, comunitarios, ya que posibilitan diversos tipos de vínculos, al tiempo que facultan gestionan y comparten contenidos.

- Blogs: son bitácoras o diarios en línea que promueven la participación, cuya característica radica en que las publicaciones se organizan en forma de cronología inversa.

- Wikis: término que proviene del hawaiano, y en castellano significa «rápido». Posibilita un espacio colaborativo donde se crean y editan contenidos alusivos a un tema de interés.

- Podcasts: integran archivos de audio y de vídeo los cuales son los registros más comunes de esta tipología de los medios sociales. Estos repertorios digitales están diseñados para que la comunidad se suscriba a sus contenidos y acceda a los ficheros en los servicios de almacenamiento.

- Foros de discusión: se entienden como puntos de encuentro e interacción para discutir sobre temas de interés particular o general.

- Comunidades de contenido: son espacios de expresión, integración y organización en múltiples formatos (imágenes, fotos, audios, vídeos) para compartir.

- Microblogging: entendidos como combinación de redes sociales y blogs, donde se comparten actualizaciones desde temas de interés. 
En suma, se advierte que, más allá de esta clasificación, entendemos estos medios sociales, como mediaciones, que recuperan lo que Martín-Barbero (1991) argumenta como una "cuestión de cultura y, por tanto, no solo de conocimientos, sino de reconocimiento" (p. 10). Es decir, un reconocimiento que posibilita desplazamiento metodológico con la idea de comprender la comunicación desde la cara no comercial. Como bien alude MartínBarbero (1991), "la recepción, el de las resistencias que ahí tienen su lugar" (p. 10). Con todo, la riqueza que ofrece no se ubica simplemente en la mera reacción u oposición, sino que se encuentra en la transformación y reconocimiento de la historia, interpretada según Martín-Barbero (1991), como aquella "reapropiación histórica del tiempo de la modernidad latinoamericana y su destiempo abriendo brecha en la tramposa lógica con que la homogeneización capitalista aparenta agotar la realidad de lo actual” (p. 10). Se trata entonces, de un reconocimiento de la comunicación como mediación socio-política desde la cual se acompañan los procesos de resistencia que des-monopolizan y des-hegemonizan, las prácticas habituales de los medios de comunicación que refieren una única versión, cual es la del poder.

De tal suerte, las dinámicas de comunicación, colaboración, cooperación, creación, co-creación, co-actuación y participación enriquecen la viabilidad para el encuentro y la movilización de resistencias que en los últimos tiempos articulan encuentro y tejido identitario y anti-identitario, de conectividad para las luchas que, como afirma Cebrián Herreros (2009), comprenden un modo de interactividad, el cual se "se instala como un proceso multidimensional que va desde los aspectos de las mediaciones, tecnológicas hasta la expresión multimedia. Con la interactividad, los cibermedios y los usuarios modifican sus relaciones" (p. 18). Es decir, las mediaciones entendidas como alternancia de la comunicación, comparten una relación bidireccional, al tiempo que fomentan la acción y participación de diversas comunidades, configurando relaciones dialógicas, que entretejen espacios abiertos para la discusión, el intercambio, la realimentación y la transformación de información.

Por lo anterior, desde el objetivo de esta investigación, referimos estos procesos como «Resistencia 2.0», a la manera de tejidos comunicativos que, en medio de la expansión extractiva, "sitúan la resistencia en la ruta de la defensa de la vida, el territorio y los bienes comunes" (Quiñones Torres, 2015, p. 75). Se trata de mediaciones que coadyuvan a las resistencias que articulan los sujetos, quienes colectivizan el encuentro alrededor de conflictos que los diversos pueblos confrontan y transforman. El fin es concebir las mediaciones como una co-actuación, desde los medios sociales, con la intención de informar, comunicar, colaborar en la creación de contenidos, e interactuar frente a una definición de realidad que suscita conflictos, como en el caso de la minería a cielo abierto, con efectos devastadores.

Es así como, en este marco de conflictos, Camacho (2011) desvela esta problemática en Costa Rica frente a las etapas de exploración y explotación de recursos naturales por parte de las transnacionales. La autora explora el impacto ambiental y social de los proyectos mineros, y demuestra que las tecnologías de información y comunicación (TIC), como 
medios, a través de dispositivos móviles, se convierten en herramientas para movilizar a las personas ante los peligros que representa este tipo de explotación. Sola Álvarez (2013) y Tetreault (2013) plantean que los medios sociales proporcionan a la población modos de sensibilización, para desafiar las políticas relativas a los proyectos megamineros en Argentina y México, respectivamente.

Osorio (2011) expone la influencia de las redes sociales y los microblogs, en los que se incluyen contenidos con imágenes, fotos, vídeos y documentación, para concienciar a los colombianos sobre los riesgos ambientales y de salud, en caso de conceder licencia ambiental para explotar oro en el Páramo de Santurbán (Santander, Colombia). Frente a esta problemática se crearon grupos públicos en Facebook denominados «SALVEMOS EL PÁRAMO DE SANTURBÁN» [Sic] y «Salvemos el AGUA y la VIDA-SANTURBÁN SANTANDER y LA COLOSA TOLIMA» [Sic], espacios virtuales que lograron vincular más de 5000 miembros para cada grupo, quienes participaron de manera online compartiendo información sobre la oposición a la minería a cielo abierto.

Asimismo, la Asociación Interamericana para la Defensa del Ambiente (AIDA, 2014) promovió dos campañas lanzadas el 1 de octubre de 2013, presentadas en el microblog Twitter (Aidaespanol, 2013), creando el hashtag \#SalvaSanturbán, para proteger el Páramo de Santurbán. No obstante, el impacto de este tuit no tuvo suficiente trascendencia, interpretada desde la medición, ya que se generaron apenas 12 retuits y 2 me gusta (ver figura 1). Sin embargo, a partir del 1 de octubre de 2013 y hasta el 26 de mayo de 2016 los tuiteros, entre la sociedad civil y organizaciones no gubernamentales (ONG), publicaron 122 entradas con el hashtag en mención.

AIDA Español

AIDA

(9)Aidaespanol

2- Seguir

\#SalvaSanturbán ¡Protejamos los páramos colombianos y su agua dulce! Tu firma puede ser el cambio:

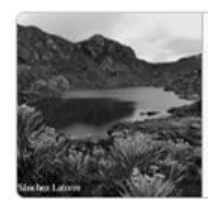

Protejamos los páramos colombianos y su agua dulce!

¡Protejamos los páramos colombianos y su agua dulce! Pidele YA a la Ministra del Ambiente que delimite bien el páramo de Santurbán! El Ministerio de Ambiente de Colombia tiene en sus... change.org

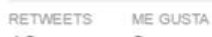

12

$8: 24-1$ oct. 2013

$4 \quad 27$

Figura 1. Tuit AIDA: Páramo de Santurbán

Fuente: Aidaespanol (2013) 
Como parte de este mismo tuit (Aidaespanol, 2013), se lanzó la segunda campaña para atraer simpatizantes que firmaran una petición denominada «Protejamos los páramos colombianos y su agua dulce!» [sic] (AIDA, 2013), a través del portal change.org.
change.org ¿ Inicia una petición Explorar O Buscar
2 Iniciar sesión
Petición para Ministra de Ambiente y Desarrollo Sostenible de Colombia Luz Helena Sarmiento y 8 otros 1 RESPUESTA

\section{Protejamos los páramos colombianos y su agua dulce!}

WDS Asociación Interamericana para la Defensa del Ambiente AIDA

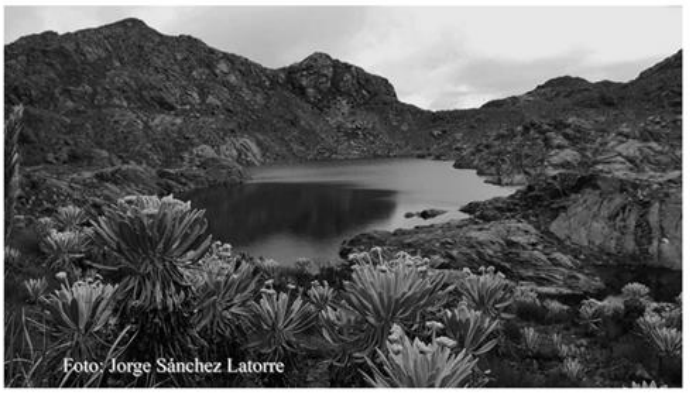

¡Protejamos los páramos colombianos y su agua dulce!

Pidele YA a la Ministra del Ambiente que delimite bien el páramo de Santurbán!

El Ministerio de Ambiente de Colombia tiene en sus manos la delimitación de los páramos y tomará la decisión muy pronto: antes de mayo, en particular para el páramo de Santurbán. Esto es importante y TÚ puedes hacer la diferencia para que la decisión sea conforme a la ciencia y en favor de los páramos, en lugar de en beneficio de grandes proyectos mineros.

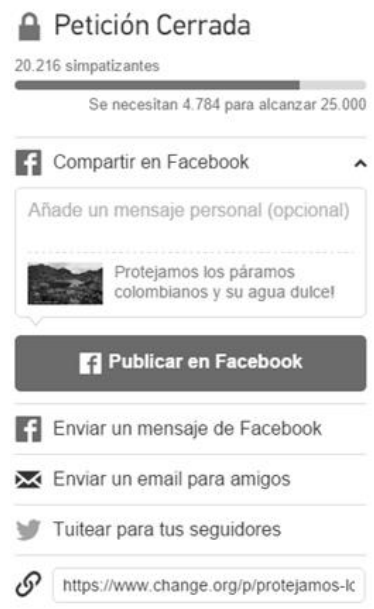

Figura 2. Firma de petición AIDA: Páramo de Santurbán Fuente: AIDA (2013)

En la figura 2, podemos apreciar que el número de personas que firmaron superó las 20.000, lo que denota un potencial en el movimiento de resistencia para proteger, no solamente el Páramo de Santurbán, sino otros que se encuentran en peligro, ya que muchos ecosistemas colombianos están concesionados a transnacionales mineras. Es decir, esta interacción que se generó a través del uso de tecnologías digitales como el correo electrónico, Facebook y Twitter, demostró principalmente la capacidad de convocatoria que tiene el sitio y, en particular, la problemática.

Para el caso de La Colosa (Tolima, Colombia), Badillo-Mendoza y Marta-Lazo (2014) esbozan una perspectiva de información alternativa a partir de los contenidos creados por quienes comparten sus posturas en plataformas como Facebook, Youtube y diversos 
blogs, cuyo propósito es originar movimientos de disconformidad y denuncias públicas contra las instituciones que avalan las estrategias y prácticas extractivas como modelo de producción y de desarrollo.

En consecuencia, se puede advertir que "la construcción mediática de la protesta social, al ser construida bajo [sic] la tachadura y el borramiento de un mito como habla despolitizada, es enfrentada desde el movimiento social como una lucha por la visibilidad y el reconocimiento" (Silva Escobar, 2015, p. 54).

\section{Resultados de la investigación}

\subsection{Diseñando desde la apropiación comunicativa e informacional en resistencia: una visión de las dinámicas propias}

Como parte de la investigación activista y militante, registramos resultados desde nuestras propias formas de mediación que, articuladas a los diversos medios sociales, coadyuvan en las luchas de resistencia antiminera. De tal modo, presentamos estas mediaciones como medios ya sea desde la acción directa, o como seguidores o como interactuantes. Con esta primera perspectiva de acción directa, destacamos el blog Acción Colectiva y Megaproyectos Mineros (2016), en el cual incidimos tanto en el diseño, como en la definición sociopolítica; en la segunda mediación, es decir, en el Facebook de Conciencia Campesina (2016), compartimos su perspectiva de lucha, somos seguidores y hacemos parte del movimiento de unidad alrededor de la resistencia. Asimismo, nos integramos como interactuantes en la red tejida desde la justicia ambiental, a partir de la cual explicamos la dinámica que allí se afianza, compartiendo la filosofía de defensa territorial que suscita y motiva resistencia.

\subsection{Encuentro Acción colectiva y megaproyectos mineros:}

\section{Blog: http://encuentromegaproyectosymineria.blogspot.com.co}

Este blog (ver figura 3) surge en mayo de 2011, como producto de un encuentro realizado para responder desde la academia a la iniciativa de organizaciones y comunidades, quienes solicitaban a los investigadores que los foros desarrollados en las universidades no siguieran reproduciendo la misma dinámica que se imponía «desde arriba», ya que estas prácticas aparentaban simetrías democráticas, por la invitación a todos los actores frente a temas como el «desarrollo minero». Con esta idea, se planteó que las comunidades quedaban rezagadas al último momento de intervención, con tiempos muy limitados, enfrentando el cansancio que llevaba a grandes deserciones del público. Lo más grave es que quienes intervenían como invitados de las grandes empresas o la institucionalidad, por lo general, presentaban sus posturas, y argumentando ser 'personas muy ocupadas', se marchaban antes de escuchar a quienes participaban desde las comunidades afectadas.

Frente a este panorama del todo asimétrico, nos dimos a la tarea desde los grupos de 
investigación: Ciencia de la Información, Sociedad y Cultura; Conflicto, Región y Sociedades Rurales y el Observatorio de Territorios Étnicos, ambos de la Pontificia Universidad Javeriana, junto con organizaciones no gubernamentales como el Colectivo de Abogados José Alvear Restrepo, el Grupo Antorcha de la Universidad Nacional, la Asociación de Cabildos de Sa'th Tama Kiwe, la Asociación de Cabildos del Norte del Cauca (ACIN), representantes de la Organización Nacional Indígena de Colombia (ONIC), el Consejo Regional Indígena del Cauca, entre otros, a organizar un evento que se llamaría: «Encuentro de Acción Colectiva y Megaproyectos Mineros», desde el cual se cambiaría esta lógica asimétrica, y por ello, el lugar principal de enunciación sería ocupado por los pueblos, las organizaciones y la academia que nos ubicamos desde otras perspectivas.

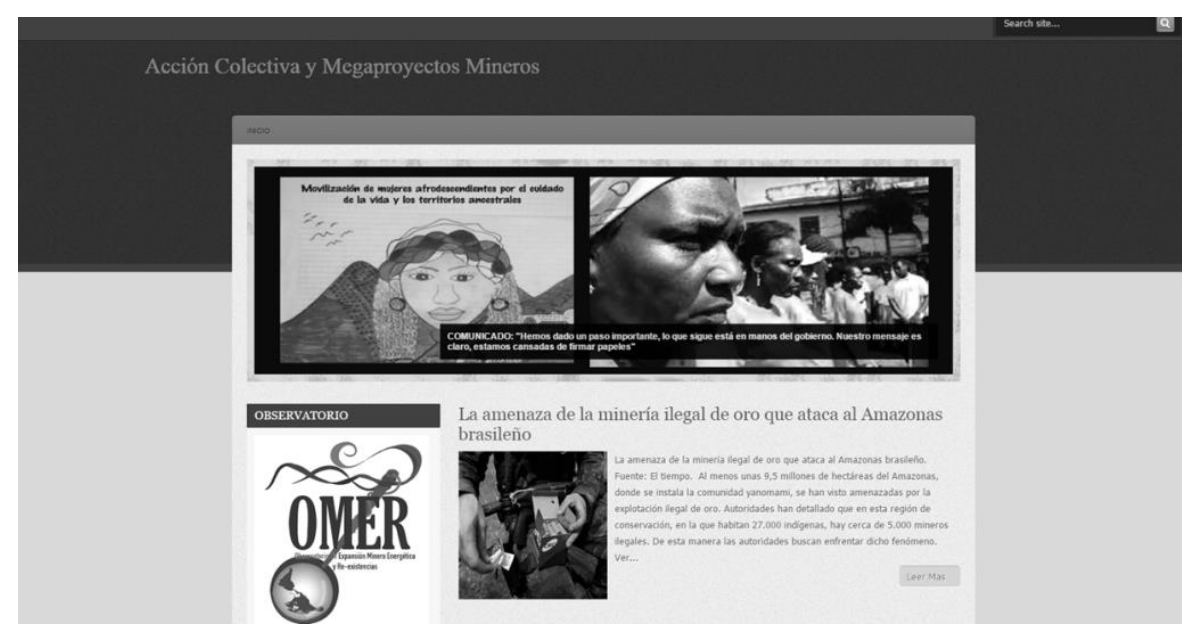

Figura 3. Blog: Acción Colectiva y Megaproyectos Mineros

Fuente: Acción Colectiva y Megaproyectos Mineros (2016)

Producto del encuentro se diseñó el Blog: http://encuentromegaproyectosymineria. blogspot.com (Acción Colectiva y Megaproyectos Mineros, 2016), cuyo enfoque se ubica en dos dimensiones: por una parte, recoge posturas y miradas respecto al impacto de las políticas mineras, con lo cual determinamos aquello que se enlaza; por otra parte, ofrece una plataforma para visibilizar e informar al mundo sobre el desarrollo de este sector y los impactos en los diversos territorios. El blog está diseñado para acceder con amigabilidad, se articulan enlaces sobre extractivismo y geopolítica; se presenta información del encuentro de acción colectiva, y de posteriores eventos que hemos organizado; igualmente, enlazamos vídeos, audios, y el manifiesto que nos identifica. Actualmente se observa un reporte de más de 169.000 visitas (26 de mayo de 2016). 


\subsection{Conciencia Campesina}

\section{Facebook: https://www.facebook.com/concienciacampesina}

Esta página de seguidores, disponible en la red social Facebook (ver figura 4), es un referente significativo en la resistencia que se configura frente a la expansión minera en Colombia, desde la cual se confronta la mina La Colosa en Cajamarca (Tolima, Colombia), mina que se proyecta en un territorio campesino conocido como despensa agrícola de Colombia ("Cajamarca: Despensa Agrícola", 2008). Cajamarca figura como el primer productor de arracacha en el nivel nacional, y segundo en frijol seco; además, se produce variedad de alimentos, especialmente de tierra fría. Se ubica en un cañón de alta riqueza hídrica que baña sus montañas, y provee el recurso a las poblaciones aledañas, y cuenta con páramos y una gran zona de reserva forestal. Por la defensa de este territorio frente a la construcción de una de las minas más grandes del mundo, se ha levantado un gran movimiento de resistencia, al que confluyen colectivos de base, algunos de los cuales se configuran como organizaciones no gubernamentales, tal como ocurre con la Organización Conciencia Campesina.

Esta es una organización que surge del campesinado agrícola, quienes logran comprender que una mina como La Colosa, a cielo abierto, que se implementa e irrumpe su territorio, genera graves conflictos ambientales y sociales que no solo transforman su vida cotidiana, sino que terminarán por desplazarlos del territorio. Con esta clara visión, los campesinos han logrado integrar a su resistencia un innumerable grupo de activistas nacionales e internacionales, entre los cuales nos encontramos quienes participamos en esta Investigación Acción Colectiva.

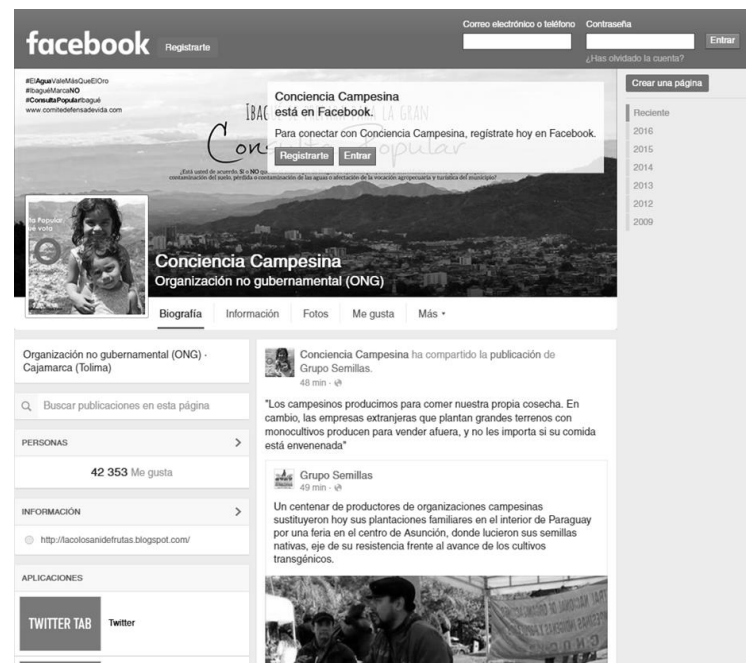

Figura 4. Página de seguidores de Facebook: Conciencia Campesina Fuente: Conciencia Campesina (2016) 
Con el fin de conectar, articular y comunicar acciones, y de integrar más seguidores que compartan la perspectiva de resistencia, se han creado redes sociales como el facebook.com/concienciacampesina (Conciencia Campesina, 2016), que tiene origen en 2009, y hoy cuenta con más de 42.000 seguidores (26 de mayo de 2016), quienes dieron la opción 'Me gusta', la cual interpretamos como una manera de seguir la iniciativa. La página de Facebook de Conciencia Campesina (2016) se comprende como una mediación en la vía sociopolítica de alternancia; allí se vinculan noticias que no se trasmiten por los canales comerciales, o las que logran pasar por estos medios y se enlazan porque refieren la problemática; también se enlaza información sobre el desarrollo de esta mina o de minas a cielo abierto en otros lugares del mundo, dando cuenta de los conflictos socio-ambientales que estos proyectos generan (J. F. Torres Fajardo, comunicación personal, 18 de mayo, 2016).

A la red social Facebook, se articulan tuits y vídeos de YouTube, que motivan la resistencia a mantenerse informada; allí se encuentran registros de las producciones propias de la resistencia, como la invitación a la «Gran Marcha Carnaval», una marcha emblemática en la que a 2015 se movilizaron más de 60 mil personas y en 2016 más de 100 mil personas.

La marcha es festejada todos los años el 5 de junio, acogiendo la celebración declarada por Naciones Unidas del «Día Mundial del Medio Ambiente», y es caracterizada por la condición de fiesta y comparsa. Asimismo, se encuentran vídeos que las comunidades campesinas realizan, así como los que hacemos conjuntamente, como es el vídeo titulado: Resistencia a la expansión minera (Quiñones Torres, 2014), con el que se ha buscado informar sobre las prácticas de resistencia de quienes estamos en contra de este tipo de proyectos expansivos.

\subsection{Red por la Justicia Ambiental en Colombia}

\section{Twitter: https://twitter.com/rjacolombia}

La Red por la Justicia Ambiental en Colombia (RJAC, s. f.) es una organización fundada en 2010, cuyo propósito se enmarca en ofrecer alternativas de respuesta a los conflictos generados por los megaproyectos extractivos y ambientales, con la finalidad de que cumplan con la legislación colombiana e internacional, relacionada con el derecho ambiental, y orientada a la protección de los derechos humanos.

Con esta orientación, y sobre la base de la defensa de la vida y el acercamiento de las comunidades (online) interesadas en el tema ambiental, la RJAC creó la cuenta en Twitter en octubre de 2012, bajo el usuario: @RJAColombia (ver figura 5). La acogida por parte de diversos actores a esta iniciativa propició alto grado de interactividad, que se demuestra con las estadísticas de participación y seguimiento. En los dos últimos años reporta 12.600 seguidores en junio de 2014, pasando a 22.820 en junio de 2015 y, a 31.065 en mayo de 2016. La Red cuenta con seguidores reconocidos en el tema ambiental, como: a) Greenpeace Colombia (@GreenpeaceColom) con más de 96.000 seguidores; b) Manuel 
Rodríguez Becerra (@manuel_rodb), exministro de Medio Ambiente en Colombia, con más de 26.100, quien se destaca por ser figura política que debate en el escenario offline y online los impactos que el extractivismo genera; c) y finalmente el Foro Nacional Ambiental (@FNAmbiental) con más de 20.200 seguidores.

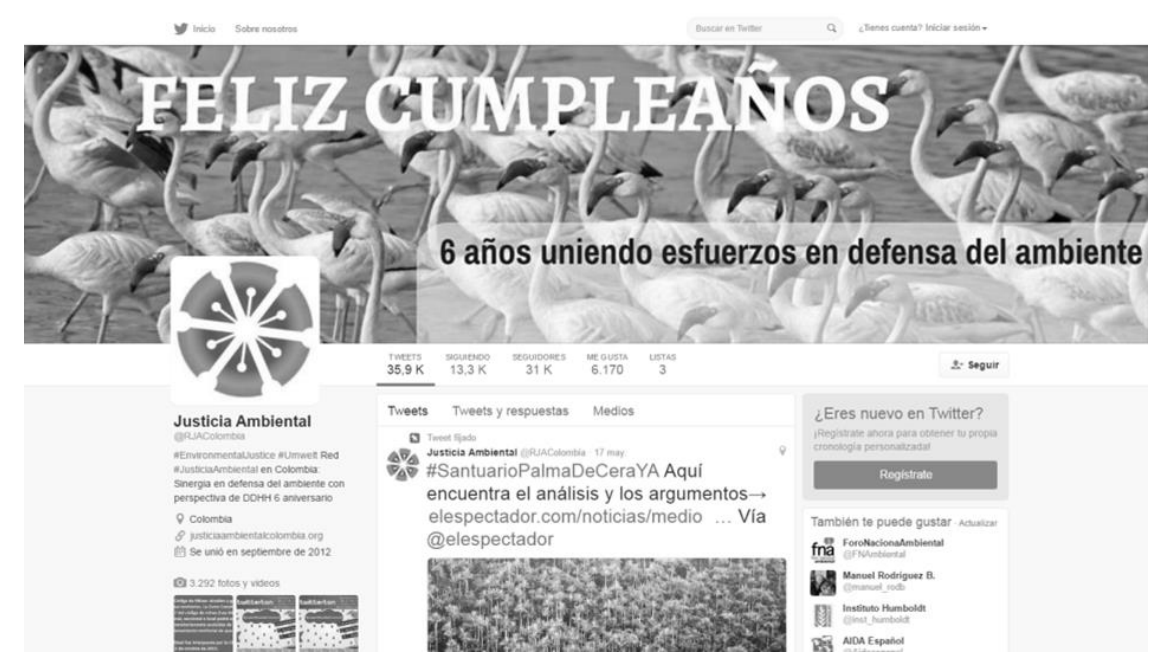

Figura 5. Cuenta de Twitter: @RJAColombia

Fuente: RJAColombia (2016)

Desde Twitter (2016), se presentó a la comunidad «socialmediática» el panel de actividades de tuits. A través de la herramienta Analytics Twitter, las personas naturales y jurídicas podrán acceder a las métricas que ofrece el microblog para calcular los resultados de sus publicaciones. La figura 6 evidencia la actividad de los tuits publicados por la RJAC, a través de un análisis realizado con la herramienta en mención. Asimismo, presenta los indicadores de impresión e interacción, mediciones de impacto que evidencia el número de veces que se han leído los tuits y su acción-relación con los usuarios. Twitter (2016) define impresiones, como la "cantidad de veces que a un usuario se le publica un Tweet en la cronología o en los resultados de búsqueda" (párr. 6), aludiendo que las interacciones son el "número total de veces que un usuario interactuó con un Tweet. Clics en cualquier lugar del Tweet, ya sea Retweets, respuestas, seguimientos, Me gusta, enlaces, cards, etiquetas, contenido multimedia insertado, nombre de usuario, foto de perfil o ampliación del Tweet" (Twitter, 2016, párr. 6). Para el caso particular, las impresiones en los últimos 28 días (hasta el 26 de mayo de 2016) de la cuenta @RJAColombia son de más de 2.600.000. Los hashtags: \#Fracking y \#ColombiaSinFranking con un impacto de más de 5000 impresiones, e interacción más de 100, en el año 2015. Para el año 2016, los hashtags: \#Junio3MarchaCarnaval y \#SOSLaCienagaAgoniza (sic), junto con \#LaCienagaEsDeTodos (sic), han tenido una sumatoria de más de 650 impresiones, con 6 interacciones hasta la fecha (26 de mayo de 2016). 
Estadisticas Inicio Tweets Audiencias Eventos Más v

Justicia Ambiental C $\checkmark$

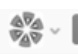

Sus Tweets consiguieron 2,6 M impresiones en este período de $\mathbf{2 8}$ días

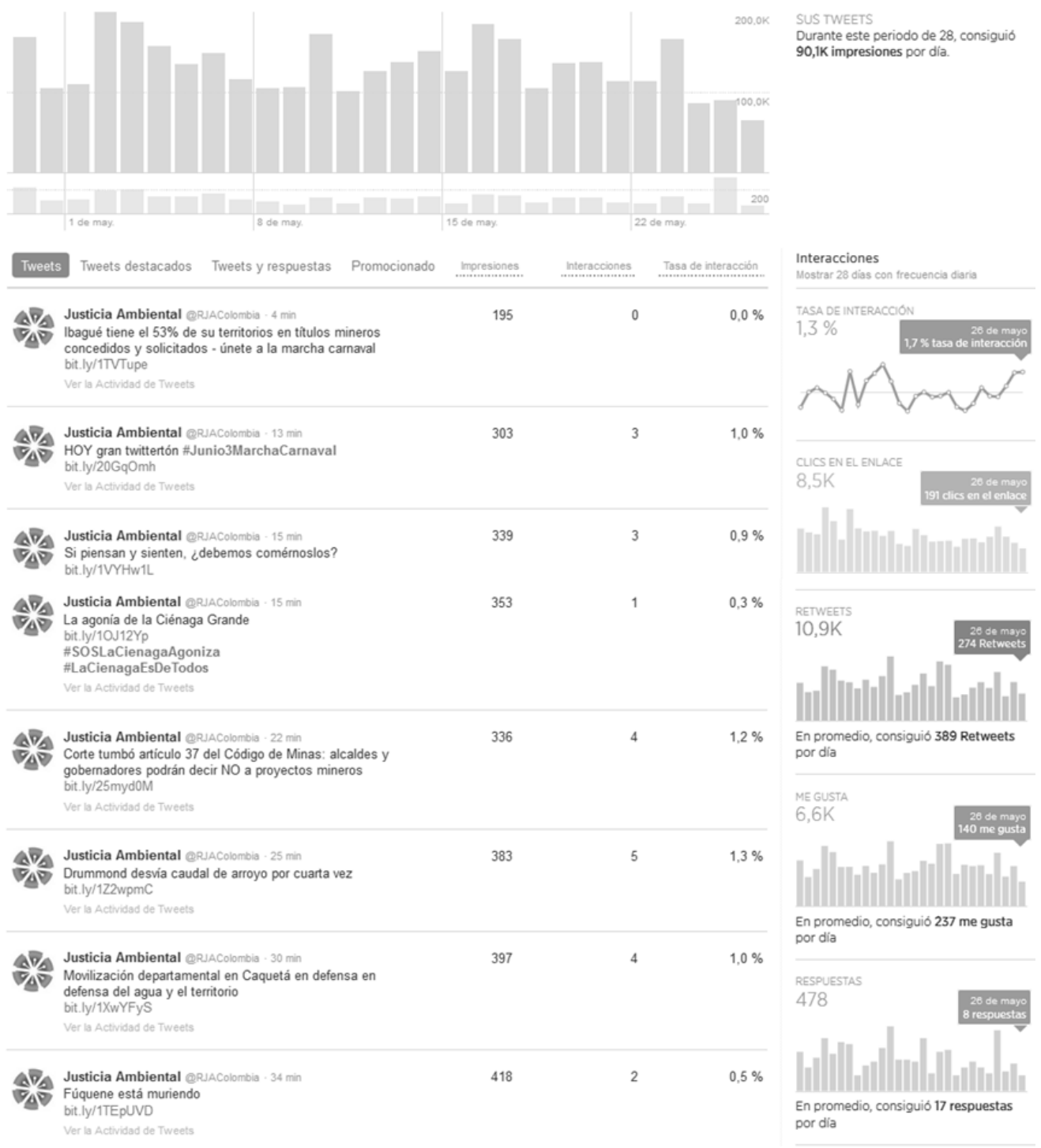

Figura 6. Actividad de tuits de la cuenta@RJAColombia Fuente: RJAColombia (2016)

La presencia en redes sociales ha contribuido a visibilizar los temas ambientales. Desde éstas, se impulsan campañas en defensa del ambiente, como las promovidas con los hashtags \#SalvaSanturbán y \#AduéñateDelPáramo. La primera, correspondiente al proyecto 
minero a cielo abierto, que se traslapa con el Páramo de Santurbán, en el departamento de Santander (Colombia), y la segunda, con el páramo de Pisba en Boyacá (Colombia).

Acogiendo la idea de Viché González (2015), en esta contemporaneidad se configuran espacios propicios para las prácticas culturales de participación, que empoderan a los sujetos a través de Internet, y utilizan medios sociales para afianzar la fuerza de los movimientos sociales, desde los cuales emerge la ciberanimación en el entorno digital, definida como:

[...] una praxis sociocultural que tiene como objetivo la mejora de la calidad de vida de los ciudadanos a través de la creación de redes y comunidades sociales de carácter solidario, con la finalidad de asegurar la sostenibilidad de esas colectividades humanas (Viché González, 2015, p. 87).

\section{Conclusiones}

La participación de los sujetos articulados a las dinámicas de resistencia permite comprender un compromiso (engagement) transitorio, y también permanente de quienes diseñan, alimentan y promueven las mediaciones como postura política, valiéndose de los diversos medios sociales, desde la alternancia que estos ofrecen. Es decir, el inconformismo manifiesto en redes sociales, microblogs, foros y demás comunidades sirve como voz de oposición y transformación para detener las dinámicas de la hegemonía corporativa y configurar dinámicas de resistencia colectiva en el escenario offline.

Las mediaciones que se expresan a través de medios sociales juegan un papel clave en la participación activa de las luchas, hacia la transformación social; por esto, el intercambio de información, así como el proceso anti-identitario o identitario de los activistas (offline y online) quienes tejen comunicativamente y resisten a proyectos devastadores como la minería a cielo abierto, resultan eficaces para mantener esta alternativa comunicativa que rompe las hegemonías mediáticas de los poderes comunicativos.

Es evidente que prácticas de investigación como el activismo militante, en temas álgidos como los megaproyectos mineros, nos ha permitido tener una visión de las mediaciones como prácticas alternativas que ofrecen transparencia. De modo que, las luchas de este estilo rompen la limitación de ciertas miradas exógenas, que observan las problemáticas con un evidente deslinde de las bases sociales, alineándose a versiones de la realidad que intentan neutralizar las apuestas de los mismos activistas, quienes finalmente gracias a los argumentos académicos y al diálogo de saberes, logran comprender lo adverso de este tipo de proyectos extractivos, que irrumpen en nuestros territorios.

Es importante resaltar que las dinámicas ofrecidas por las mediaciones como apuesta deshegemonizante, a través de la creación y uso de los medios sociales, dan como resultado un importante apoyo comunicativo que, si bien no reemplaza en estos casos la presencia activa de las resistencias, sí posibilita el encuentro interactivo y virtual, como otra forma de lucha que, viabiliza información técnica y cultural que viajando por estas vías, es transformada en conocimiento, forjando argumentos contundentes, para la contención de esta apuesta extractiva. 
Los medios sociales que se han presentado demuestran que la interacción por estas vías ha incidido efectivamente en el crecimiento participativo de actividades específicas, como la Marcha Carnaval celebrada en el Departamento del Tolima (Colombia). Asimismo, la asistencia a eventos académicos o encuentros de organizaciones de base, y de organizaciones no gubernamentales, convocadas a través de estos medios, ha permitido avanzar en el conocimiento sobre los impactos mineros, rompiendo con la dependencia de los medios comerciales, los cuales, alineados con el gobierno de turno y con las políticas impuestas, alimentan un modelo específico de desarrollo.

\section{Referencias bibliográficas}

Acción Colectiva y Megaproyectos Mineros [Blog]. (2016). Recuperado de http://encuentromegaproyectosymineria. blogspot.com.co

Aidaespanol. (1 de octubre de 2013). \#SalvaSanturbán iProtejamos los páramos colombianos y su agua dulce! Tu firma puede ser el cambio: http://chn.ge/18GdghW [Tuit]. Recuperado de https:// twitter.com/Aidaespanol/status/385032364528660482

Asociación Interamericana para la Defensa del Ambiente [AIDA]. (2011). Protejamos los páramos colombianos y su agua dulce! Recuperado de https://www.change.org/p/protejamos-los-páramos-colombianosy-su-agua-dulce

Asociación Interamericana para la Defensa del Ambiente [AIDA]. (2014). iProtejamos los páramos colombianos y su agua dulce! Recuperado de http://www.aida-americas.org/es/\%C2\%Al protejamoslos-p\%C3\%Al ramos-colombianos-y-su-agua-dulce

Badillo-Mendoza, M. E., E Marta-Lazo, C. (2014). Ciberciudadanía y minería: Lineamientos conceptuales y prácticas, caso La Colosa, Tolima, Colombia. Revista Entramado, 10(2), 238-249. Recuperado de http://www.scielo.org.co/pdf/entra/v10n2/v10n2a15.pdf

Botero, P. (2012). Investigación y acción colectiva "IAC". Una experiencia de investigación militante. Utopía y Praxis Latinoamericana, 17(57), 31-47. Recuperado de http://www.redalyc.org/articulo. oa? id $=27922814004$

Cabrera, M. (2014, 28 de julio). Intervención pacto de cumplimiento. Acción Popular de solicitud del cierre de la ventanilla minera. Audiencia Acción Popular. Documento interno.

Cajamarca: Despensa Agrícola. (2008). Boletín Mensual: Abastecimiento de Alimentos en los Principales Mercados, 4(3), 1-9. Recuperado de http://agronet.gov.co/www/docs_agronet/2008106152754_ Abastecimiento_AbrilM.pdf

Camacho, K. (2011). Costa Rica: Las TIC ayudan a derrotar el proyecto de minería a cielo abierto. Recuperado de http://giswatch.org/sites/default/files/apc_gisw_2011_es_costa_rica.pdf

Cebrián Herreros, M. (2009). Comunicación interactiva en los cibermedios. Comunicar: Revista Científica de Comunicación y Educación, 17(33), 15-24. doi: 10.3916/c33-2009-02-001

Conciencia Campesina. (2016). En Facebook [Página de seguidores]. Recuperado de https://www.facebook. com/concienciacampesina

Congreso de la República de Colombia. (2001, 8 de septiembre). Ley 685 de 2001: por la cual se expide el Código de Minas y se dictan otras disposiciones. Diario Oficial, 137(44.545), 1-23. 
Congreso de la República de Colombia. (2015, 9 de junio). Ley 1753 de 2015 (junio 9) por la cual se expide el Plan Nacional de Desarrollo 2014-2018 "Todos por un nuevo país". Diario Oficial, 151(49.538), 1-44.

Consejo de Estado de Colombia, Sala de lo Contencioso-Administrativo. (2014). Solicitud de suspensión provisional que elevó la parte actora respecto del Decreto 934 de 2013, << Por el cual se reglamenta el artículo 37 de la Ley 685 de 2001 >>. Recuperado de http://www.colombiapuntomedio.com/Portals/0/ Archivos2014/DocumentosOfic2014/Fallo\%20Consejo\%20de\%20Estado\%20Decreto\%20934\%20 de\%202013.pdf

Delgado, J., E Gutiérrez, J. (1999). Métodos y técnicas de investigación cualitativa en ciencias sociales. Madrid, España: Síntesis.

Departamento Nacional de Planeación de Colombia [DNP]. (2015). Plan Nacional de Desarrollo, 2014-2018. Todos por un nuevo país. Recuperado de https://colaboracion.dnp.gov.co/CDT/Prensa/ArticuladoVF.pdf

Garay Salamanca, L. J. (Dir.). (2013). Minería en Colombia. Fundamentos para superar el modelo extractivista. [Bogotá, D. C.]: Imprenta Nacional. Recuperado de http://www.colombiapuntomedio.com/Portals/0/ Archivos2013/Miner\%C3\%ADa.pdf

Hoyos, C. (2000). Un modelo para investigación documental. Guía teórico-práctica sobre construcción de Estados del Arte. Medellín: Señal.

Impactos de las extracciones mineras en el desarrollo rural en Colombia, Los. (2014). Recuperado de http://www. cid.unal.edu.co/cidnews/index.php/inequidad-gran-problema-de-la-salud-en-bogota/2393-losimpactos-de-las-extracciones-mineras.html

Mayfield, A. (2008). What is social media? Recuperado de http://www.icrossing.com/uk/sites/default/ files_uk/insight_pdf_files/What\%20is\%20Social\%20Media_iCrossing_ebook.pdf

Martín-Barbero, J. (1991). De los medios a las mediaciones: Comunicación, cultura y hegemonía (2. ${ }^{a}$ ed.). Barcelona: Gustavo Gili.

Menéndez Echavarría, A. L., E Sánchez Hernández, C. M. (2013). Uso de plataformas social media en la práctica docente universitaria: investigación biográfico-narrativa en un estudio de caso. Signo y Pensamiento, 32(63), 152 168. Recuperado de http://revistas.javeriana.edu.co/index.php/ signoypensamiento/article/view/6948/5538

Osorio, C. (2011, 9 de marzo). Los poderes detrás del páramo de Santurbán. La Silla Vacía. Recuperado de http://lasillavacia.com/historia/los-poderes-detras-del-paramo-de-santurban-22387

Pardo, A (2015). Incidencia del modelo minero en la economía colombiana. Recuperado de http://www. colombiapuntomedio.com/Portals/0/Archivos2015/NuestrosDocumentos2015/Incidencia\%20 del\%20modelo\%20mineros\%20en\%20la\%20econom\%C3\%ADa\%20colombiana.pdf

Quiñones Torres, A. (2015). Geopolítica de los conflictos socioambientales: resistencia a la expansión minera. Memoria y Sociedad, 19(39), 73-92 doi 10.11144/Javeriana.mys19-39.gcsr

Quiñones Torres, A. (2014). Resistencia a la expansión minera. Proyecto vinculado a Tesis Doctoral: Resistencias Frente a la Expansión Minera. Los casos de la Toma, La Colosa, Sa'th Tama Kiwe [Archivo de video]. Recuperado de https://www.youtube.com/watch?v=y9005vVwFnE

Red por la Justicia Ambiental en Colombia [RJAC]. (s.f.). ¿Qué es? Recuperado de http:// justiciaambientalcolombia.org/about/ 
RJAColombia. (2016). Red por la Justicia Ambiental en Colombia [Cuenta de Twitter]. Recuperado de https://twitter.com/rjacolombia

RJAColombia. (2016). [Actividad de tuits de la cuenta@RJAColombia] [Imagen]. Recuperado de https:// twitter.com/rjacolombia

Saade Hazin, M. (2013). Desarrollo minero y conflictos socioambientales: Los casos de Colombia, México y el Perú. Santiago de Chile: Naciones Unidas. Recuperado de http://repositorio.cepal.org/bitstream/ handle/11362/5369/LCL3706_es.pdf?sequence $=1$

Salvemos el AGUA y la VIDA - SANTURBÁN SANTANDER y LA COLOSA TOLIMA. [ca. 201 1]. En Facebook [Grupo público]. Recuperado de https://www.facebook.com/groups/salvemoselaguaylavida

SALVEMOS EL PARAMO DE SANTURBAN. [ca. 2011]. En Facebook [Grupo público]. Recuperado de https://www.facebook.com/groups/20614423866

Silva Escobar, J. P. (2015). La fabricación mediática de la protesta social. Notas acerca de la conformación de una opinión pública despolitizada y estetizante. Anagramas, rumbos y sentidos de la comunicación, 13(26), 43-56. Recuperado de http://revistas.udem.edu.co/index.php/anagramas/ article/view/1181/1140

Sola Álvarez, M. (2013). La disputa por la licencia social de los proyectos mineros en La Rioja, Argentina. Letras Verdes, (14), 27-47. doi 10.17141/letrasverdes.14.2013.991

Tetreault, D. (2013). La megaminería en México. Reformas estructurales y resistencia. Letras Verdes, (14), 214-232. doi 10.17141/letrasverdes.14.2013.1045

Twitter. (2016). Panel de actividad de Tweets. Recuperado de https://support.twitter.com/articles/2017 1993

Viché González, M. (2015). El empoderamiento de los ciudadanos internet. Revista Internacional de Pensamiento Político, 10, 85-100. Recuperado de http://pensamientopolitico.org/Descargas/RIPP10. pdf\#page $=85$ 
